\title{
Testicular Plasmacytoma: Appearance on Gray-scale and Power Doppler Sonography
}

\author{
Ronald O. Bude, MD \\ Department of Radiology, TC 2910K, University of Michigan Medical Center, 1500 East Medical Center Drive, \\ Ann Arbor, Michigan 48109-0326
}

Received 17 November 1998; accepted 9 February 1999

\begin{abstract}
A case of testicular plasmacytoma, a very rare neoplasm, is presented. The gray-scale and power Doppler sonographic findings are illustrated. The lesion appeared as a hypoechoic, intratesticular mass that was markedly hypervascular. When marked hypervascularity is present in a testicular mass in a patient unlikely to have orchitis on clinical grounds, plasmacytoma should be considered in the differential diagnosis. (C) 1999 John Wiley \& Sons, Inc. J Clin Ultrasound 27:345-346, 1999.
\end{abstract}

Keywords: testis, neoplasms; testis, ultrasonography; power Doppler ultrasonography

$\mathrm{T}_{\mathrm{s}}$ esticular plasmacytoma is a very rare neoplasm, with few previous case reports. ${ }^{1-5}$ Its power Doppler appearance has not been described. This report describes the gray-scale and power Doppler sonographic findings in a case of testicular plasmacytoma.

\section{CASE REPORT}

A 41-year-old man presented 1.5 years prior to scrotal sonography with a paraspinous thoracic plasmacytoma, which was successfully treated with radiation. Over the next year, he was successfully treated with radiation for recurrences to the right supraclavicular region and left foot. Scrotal sonography was prompted by clinical discovery of a palpable left testicular mass. Sonography using a LOGIC $700 \mathrm{MR}$ ultrasound scanner (GE Medical Systems, Milwaukee, WI) disclosed a 3-cm, solitary, slightly heterogeneous, hypoechoic left testicular mass in gray-scale mode with

Correspondence to: R. Bude

(ㄷ) 1999 John Wiley \& Sons, Inc.

CCC 0091-2751/99/060345-02 marked hypervascularity in power Doppler mode (Figures 1 and 2). Left orchiectomy with histopathologic analysis of the mass revealed plasmacytoma.

\section{DISCUSSION}

Extramedullary plasmacytoma is rare, most often occurring in the nasopharynx. ${ }^{6}$ Testicular plasmacytoma is extremely rare; it was found in only 7 of approximately 6,000 testicular and peritesticular tumors at the Armed Forces Institute of Pathology. ${ }^{7}$

While previous case reports have documented the gray-scale sonographic features of testicular plasmacytoma, ${ }^{1-5}$ this case report demonstrates

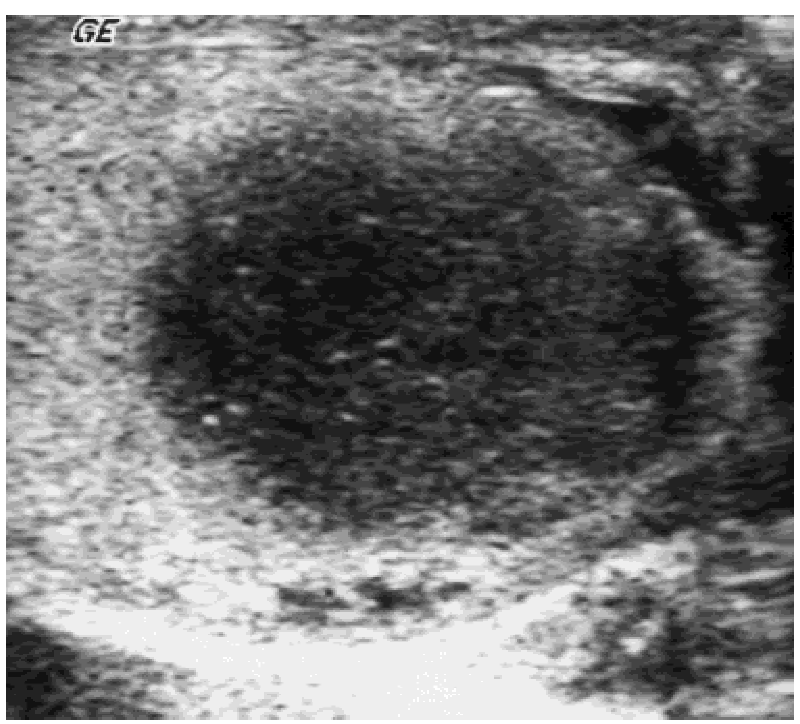

FIGURE 1. Longitudinal sonogram showing the plasmacytoma as a slightly heterogeneous, hypoechoic testicular mass. 


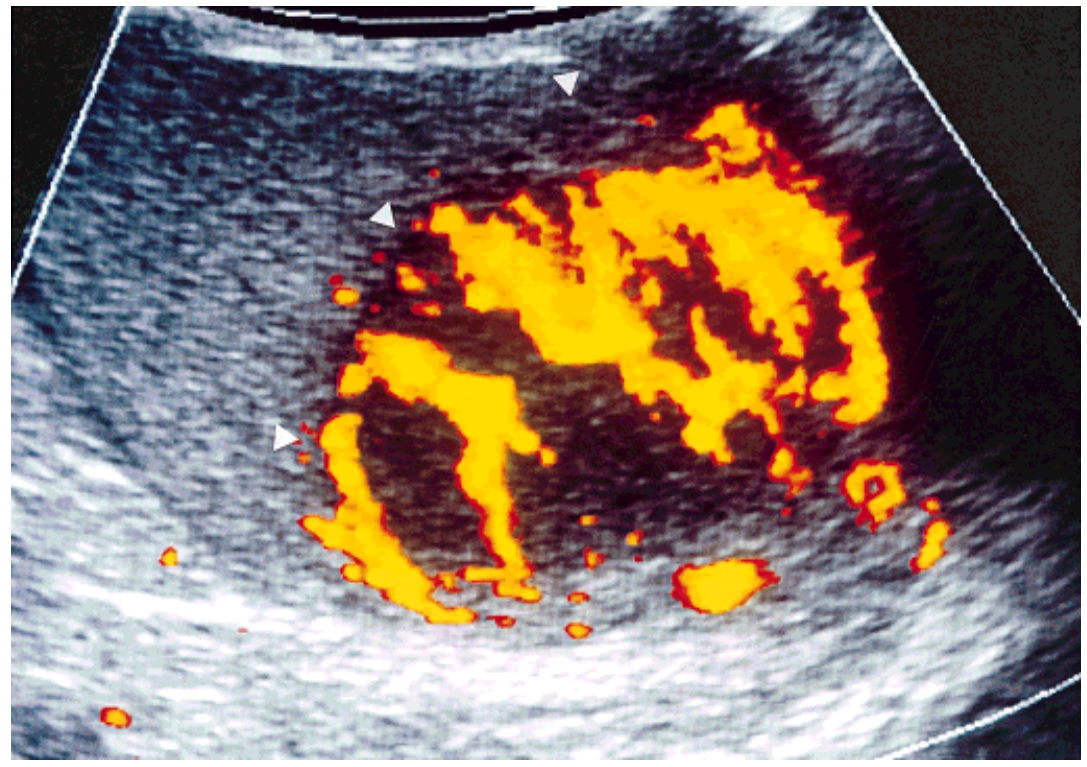

FIGURE 2. Power Doppler sonogram of the midportion of the plasmacytoma in the longitudinal plane showing marked hypervascularity (arrowheads indicate margins of the mass).

the hyperemia present in this tumor. In this regard, the hyperemia is similar to that seen with testicular lymphoma or leukemia. ${ }^{8,9}$ The degree of hyperemia demonstrated in this case is much greater than our usual experience with testicular germ cell neoplasms. When marked hypervascularity is present in a testicular mass in a patient unlikely to have orchitis on clinical grounds, plasmacytoma should be considered in the differential diagnosis.

\section{REFERENCES}

1. Gale JT, Bowie JD, Mahony BS. Myeloma of the testicle: sonographic appearance. J Clin Ultrasound 1987; 15:280.

2. Benson CB, Deligdish CK, Loughlin KR. Sonographic detection of testicular plasmacytoma. J Clin Ultrasound 1987;15:490.

3. Cavanna L, Fornari F, Civardi G, et al. Extramed- ullary plasmacytoma of the testicle. Blut 1990;60: 328.

4. Campani R, Carella E, Moschini GL, et al. US study of testicular plasmacytoma: a case report [in Italian]. Radiol Med (Torino) 1990;79:247.

5. Croft GV, Albertyn LE. Sonographic appearance of plasmacytoma of the testis. Australas Radiol 1992; 36:265.

6. Kapadia SB, Desai U, Cheng VS. Extramedullary plasmacytoma of the head and neck: a clinicopathologic study of 20 cases. Medicine 1982;61:317.

7. Levin HS, Mostofi FK. Symptomatic plasmacytoma of the testis. Cancer 1970;25:1193.

8. Mazzu D, Jeffrey RB Jr, Ralls PW. Lymphoma and leukemia involving the testicles: findings on grayscale and color Doppler sonography. AJR Am J Roentgenol 1995;164:645.

9. Horstman WG, Middleton WD, Melson GL, et al. Color Doppler US of the scrotum. Radiographics 1991;11:941. 